\title{
Effect of Ultrasound on Heterogeneous Nucleation in TIG Welding of Al-Li Alloy
}

\author{
Qi-Hao Chen ${ }^{1} \cdot$ San-Bao Lin ${ }^{1} \cdot$ Chun-Li Yang ${ }^{1} \cdot$ Cheng-Lei Fan $^{1} \cdot$ Hong-Liang Ge ${ }^{1}$
}

Received: 20 April 2016/Revised: 7 June 2016/Published online: 12 October 2016

(C) The Chinese Society for Metals and Springer-Verlag Berlin Heidelberg 2016

\begin{abstract}
The effect of ultrasound on heterogeneous nucleation in a tungsten inert gas (TIG) weld pool of 2195 Al-Li alloy has been investigated by a series of experiments. An ultrasonic vibration was imposed on the surface of base material before turning off the welding arc during the TIG welding implemented at a fixed point. The results suggest that ultrasound could promote heterogeneous nucleation in the TIG weld pool of $2195 \mathrm{Al}-\mathrm{Li}$ alloy. The grain around the fusion zone is changed from a column grain to an equiaxed grain after applying the ultrasonic treatment. To study the influencing mechanism of ultrasound on heterogeneous nucleation, further investigations were implemented where the welding arc was turned off after turning off the ultrasonic power. The results show that the equiaxed grain around the fusion zone disappeared gradually with an increase in heat input after turning off the ultrasonic power. It suggests that ultrasound could promote the heterogeneous nucleation particle to nucleate in advance before turning off the welding arc and the crystal nucleus could again be melted with an increase in heat input after turning off the ultrasonic power. Moreover, the effects of the welding current and ultrasonic amplitude on heterogeneous nucleation in the weld pool of $2195 \mathrm{Al}-\mathrm{Li}$ alloy were also investigated. Possible influencing mechanism of the welding current and ultrasonic amplitude on heterogeneous nucleation was discussed.
\end{abstract}

KEY WORDS: Ultrasound; TIG welding; Grain; Al-Li alloy

\section{Introduction}

A fine and equiaxed grain structure is beneficial to the improvement of mechanical properties of tungsten inert gas (TIG) welded joints [1]. In general, two different approaches to grain refinement have been pursued: chemically stimulated and physically induced [2-4]. The physical route mainly relies on the use of an external field. The physical route is more advanced than the chemical method

Available online at http://link.springer.com/journal/40195

Chun-Li Yang

yangc19@hit.edu.cn

1 State Key Laboratory of Advanced Welding and Joining, Harbin Institute of Technology, Harbin 150001, China because it is not limited by the chemical compositions of the alloys to be treated [5].

Al-Li alloy is a light metallic material and possesses wide applications [6]. TIG welding is one of the commonly used fusion welding processes. In general, the conventional TIG welded joints of $\mathrm{Al}-\mathrm{Li}$ alloys possess coarse microstructures that result in low mechanical properties of the TIG welded joints. The application of Al-Li alloy has been limited by the low strength of the welded joints. Thus, refining the grain of TIG welded joints of Al-Li alloys is an important measure for improving the mechanical properties of welded joints.

Ultrasonic treatment during TIG welding is a simple and effective physical method to refine the grain of the TIG welded joints. Experimental study of the welding structure indicates grain refinement by the ultrasonic emission of the modulated arc [7]. Watanabeet et al. [8] suggested that the 
ultrasonic vibration encouraged equiaxed grains to form in the central region of the weld metal by introducing directly ultrasonic vibration into the weld pool using ultrasonically vibrating filler metal. Yuan et al. [9] investigated the effect of the ultrasound on grain refining in arc welds of $\mathrm{Mg}$ alloys by dipping an ultrasonic probe in the weld pool to stir producing effective grain refining in arc welds of $\mathrm{Mg}$ alloys. However, these investigations mainly focus on the final result of grain refinement, and it is unclear how the grain is refined. Recently, increased attention has focused on the mechanism of grain refinement of TIG welded joints.

The grain refinement mechanism under the influence of the ultrasound has been investigated more in the casting field. High-frequency and high-amplitude oscillations result in an ultrasonic cavitation and agitation in metal melt [10]. The grain refinement mechanisms with ultrasonic treatment mainly consist of an increased nucleation rate and dendrite fragmentation [11, 12]. In the former case, the collapse of cavity or bubble can generate extremely large pressure spikes to increase the freezing temperature of liquid, and the expansion of the cavity could also reduce the surface temperature of bubble; thus, nucleation could be promoted [13-15]. Moreover, cavitation could also improve the wettability of high-temperature stable particles that exist in the melt and turn them into nucleation sites $[16,17]$. In the latter case, the cavitation bubbles become unstable and consequently collapse when cavitation bubbles grow to a critical size, producing powerful micro-jets and shock waves. The interaction of the large-amplitude shock waves and the micro-jets has the potential to generate hydrodynamic pressure peaks of up to several hundreds of MPa, which could break the dendrites [18].

This paper aims to investigate the effect of the ultrasound on heterogeneous nucleation in TIG welding of $2195 \mathrm{Al}-\mathrm{Li}$ alloy. More precisely, the aim is to understand the mechanism of grain refinement for TIG welded joint of $2195 \mathrm{Al}-\mathrm{Li}$ alloy in an ultrasonic field. In this work, the effect of dendrite fragmentation on grain refinement of TIG welded joint is excluded by the method that the ultrasonic treatment is only implemented before turning off the welding arc.

\section{Materials and Methodology}

The materials used in this study were the $2195 \mathrm{Al}-\mathrm{Li}$ alloy and 1A99 Al alloy of thickness $2 \mathrm{~mm}$. The chemical composition is provided in Table 1 . The impurity content in $1 \mathrm{~A} 99 \mathrm{Al}$ alloy is lower than that in $2195 \mathrm{Al}-\mathrm{Li}$ alloy. The aluminum content in 1 A99 $\mathrm{Al}$ alloy is $99.99 \%$.

A schematic of the setup is shown in Fig. 1. The experimental setup consists of a TIG welding system and an ultrasonic system. In this work, the plate welding was
Table 1 Chemical composition of the studied materials (wt $\%$ )

\begin{tabular}{lllllllll}
\hline Material & $\mathrm{Li}$ & $\mathrm{Ag}$ & $\mathrm{Si}$ & $\mathrm{Fe}$ & $\mathrm{Cu}$ & $\mathrm{Ti}$ & $\mathrm{Zr}$ & $\mathrm{Al}$ \\
\hline 2195 & 1.00 & 0.40 & 0.03 & 0.16 & 4.02 & 0.068 & 0.11 & $\mathrm{Bal}$ \\
$1 \mathrm{~A} 99$ & - & - & 0.003 & 0.003 & 0.005 & - & - & $\mathrm{Bal}$ \\
\hline
\end{tabular}

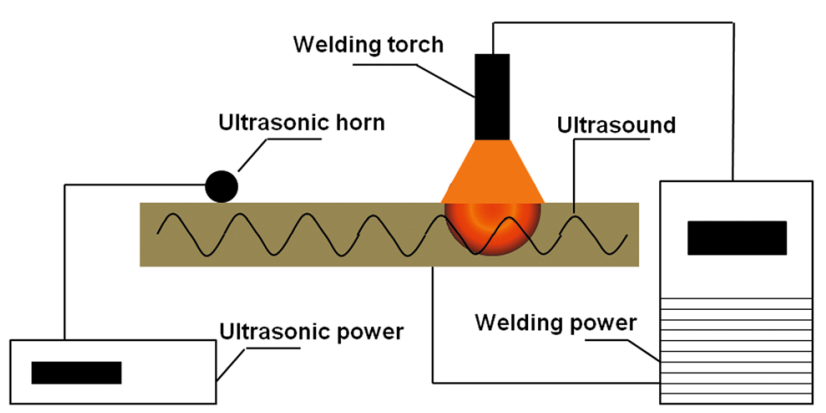

Fig. 1 Schematic illustration of the experimental setup

implemented at a fixed point without a filler wire. A Miller Dynasty $350 \mathrm{AC}$ welder was used. The duty cycle was 75 percent, and the frequency was $100 \mathrm{~Hz}$. The shielding gas was $\mathrm{Ar}$, and the output flow rate was $15 \mathrm{~L} / \mathrm{min}$. Ultrasonic system that produced $35-\mathrm{kHz}$ vibrations was used. The distance between the ultrasonic input position and the welding position remained constant at a distance of $11 \mathrm{~cm}$.

The effects of ultrasound on the microstructure of TIG welded joint of $2195 \mathrm{Al}-\mathrm{Li}$ alloy and 1A99 Al alloy were investigated. The TIG welding arc and the ultrasonic power were turned on and off simultaneously to exclude the disturbance of dendrite fragmentation. The welding and ultrasonic treatment times were $17 \mathrm{~s}$. The welding current was $80 \mathrm{~A}$, and the ultrasonic amplitude was $11.4 \mu \mathrm{m}$.

The influencing mechanism of ultrasound on heterogeneous nucleation in TIG welding of $2195 \mathrm{Al}-\mathrm{Li}$ alloy was further investigated. Two experiments were carried out in which the ultrasonic power was turned off before turning off the welding arc. The ultrasonic power was turned off at $17 \mathrm{~s}$. The experimental parameters are shown in Tables 2 and 3. The first experiment was that the welding arc was turned off at different time after turning off the ultrasonic power, and the welding current remained constant in the process of TIG welding (Table 2). The second experiment was that the welding current was increased gradually after turning off the ultrasonic power, and the welding arc is turned off at $22 \mathrm{~s}$ (Table 3).

The effects of ultrasonic amplitude and welding current on heterogeneous nucleation in TIG welding of $2195 \mathrm{Al}-\mathrm{Li}$ alloy were investigated. The output amplitude of the ultrasonic equipment could be adjusted by regulating the output percentage of ultrasonic amplitude. 0, 5, 10, 20 and $30 \%$ were chosen, and the corresponding ultrasonic 
Table 2 Experimental parameters in TIG welding with different welding time

\begin{tabular}{llll}
\hline $\begin{array}{l}\text { Experimental } \\
\text { number }\end{array}$ & $\begin{array}{l}\text { Welding } \\
\text { current }(A)\end{array}$ & $\begin{array}{l}\text { Ultrasonic } \\
\text { amplitude }(\mu \mathrm{m})\end{array}$ & $\begin{array}{l}\text { Turn-off time of } \\
\text { welding power }(\mathrm{s})\end{array}$ \\
\hline S-1 & 66 & 7.2 & 17 \\
S-2 & 66 & 7.2 & 21 \\
S-3 & 66 & 7.2 & 25 \\
S-4 & 66 & 7.2 & 29 \\
\hline
\end{tabular}

Table 3 Experimental parameters in TIG welding with different welding currents

\begin{tabular}{|c|c|c|c|}
\hline \multirow[t]{2}{*}{ Experimental number } & \multicolumn{2}{|c|}{ Welding current (A) } & \multirow{2}{*}{$\begin{array}{l}\text { Ultrasonic } \\
\text { amplitude }(\mu \mathrm{m})\end{array}$} \\
\hline & $0-17 \mathrm{~s}$ & $17-22 \mathrm{~s}$ & \\
\hline S-5 & 60 & 60 & 7.2 \\
\hline S-6 & 60 & 70 & 7.2 \\
\hline S-7 & 60 & 75 & 7.2 \\
\hline
\end{tabular}

amplitude is $0,7.2,8.4,8.8$ and $11.4 \mu \mathrm{m}$, respectively. The relation between the ultrasonic amplitude and the output percentage of ultrasonic amplitude is not linear strictly. Four different welding currents were chosen in the welding process. The experimental parameters are shown in Table 4.

Grain observation of TIG welded joint was performed using optical microscope. The section of the welded joint was ground, polished and chemically etched. Etching of the $2195 \mathrm{Al}-\mathrm{Li}$ alloy was implemented by Keller's reagent, and etching of the $1 \mathrm{~A} 99 \mathrm{Al}$ alloy was implemented by electrolytically oxidizing at $20 \mathrm{VDC}$ in a 3 pct $\mathrm{HBF}_{4}$ water solution. Grain size was measured using the linear intercept method.

\section{Results and Discussion}

\subsection{Microstructural Observations Before and After Ultrasound}

The TIG welding arc and the ultrasonic power were turned off at the same time in the TIG welding process. The weld pool was only treated with ultrasound before turning the welding arc off. Figure 2 shows the typical microstructures on the cross sections of TIG welded joint of $\mathrm{Al}$ alloy.
The results show that the column grain becomes the equiaxed grain around the fusion zone for the $2195 \mathrm{Al}-\mathrm{Li}$ alloy after applying an ultrasonic treatment. The microstructure is not changed, and the grain is still the column grain around the fusion zone for the $1 \mathrm{~A} 99 \mathrm{Al}$ alloy after applying an ultrasonic treatment. The experimental process is similar to the ultrasonic melt treatment in the cast field. Puga et al. [15] applied the ultrasonic melt treatment isothermally above the liquidus temperature of the AlSi9Cu3 alloy, and the results also showed that the ultrasonic vibration promoted the formation of small grains. Huang et al. [19] investigated the effect of ultrasonic melt treatment on grain refinement of pure aluminum; however, the result is different from our study. Their experimental results suggest that the grains of pure aluminum could also be refined by applying the ultrasonic melt treatment. The reason about this different is unknown and need to be investigated further.

Nucleation in the weld pool includes the heterogeneous nucleation and homogeneous nucleation. The difference between the $1 \mathrm{~A} 99 \mathrm{Al}$ and the $2195 \mathrm{Al}-\mathrm{Li}$ alloys is the different impurity contents. The impurity content of the $2195 \mathrm{Al}-\mathrm{Li}$ alloy is higher than that of the 1A99 Al alloy. There are more nucleation sites (such as $\mathrm{Al}_{3} \mathrm{Zr}$ and $\mathrm{Al}_{3} \mathrm{Ti}$ ) in the $2195 \mathrm{Al}-\mathrm{Li}$ alloy [20-23], and there are few nucleation sites in the 1A99 $\mathrm{Al}$ alloy. The nucleation is mainly the heterogeneous nucleation for the $\mathrm{Al}-\mathrm{Li}$ alloy. There is no significant change for the microstructure of the welded joint of pure aluminum after applying ultrasonic treatment, suggesting that ultrasound could promote the heterogeneous nucleation rather than the homogeneous nucleation in the weld pool of $\mathrm{Al}$ alloy.

\subsection{Influence of Ultrasound on Heterogeneous Nucleation of the Al-Li Alloy}

\subsubsection{Effect of Heat Input on Microstructure Around the Fusion Zone}

Influence mechanism of ultrasound on the heterogeneous nucleation of the $2195 \mathrm{Al}-\mathrm{Li}$ alloy was further investigated. The ultrasonic power was turned off before turning off the welding arc in the experimental process. Two experimental conditions were chosen, and the experimental parameters are shown in Tables 2 and 3. The first experiment is that the welding current is kept constant and the

Table 4 Experimental parameters about the effect of welding current and welding time on heterogeneous nucleation

\begin{tabular}{lllllllll}
\hline Experimental parameter & \multicolumn{2}{l}{ Experimental number } & & & \\
\cline { 2 - 7 } & 1 & 2 & 3 & 4 & 5 & 6 & 7 \\
\hline Welding current $(\mathrm{A})$ & 40 & 50 & 60 & 70 & 70 & 70 & 70 \\
Ultrasonic amplitude $(\mu \mathrm{m})$ & 7.2 & 7.2 & 7.2 & 7.2 & 0 & 8.4 & 8.8 & 11.4 \\
\hline
\end{tabular}



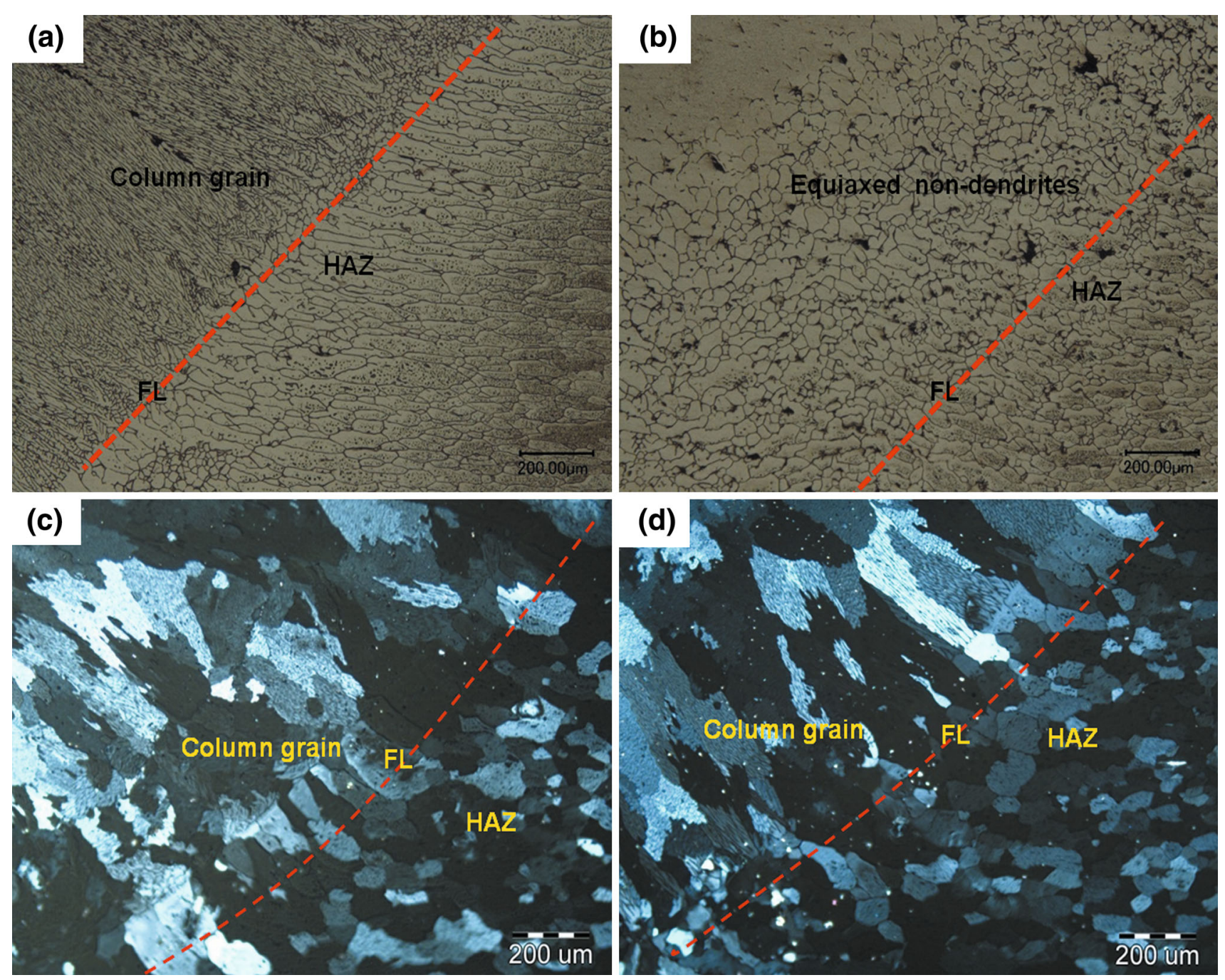

Fig. 2 Microstructures around the fusion zone of 2195 Al-Li alloy a, b and 1A99 Al alloy $\mathbf{c}, \mathbf{d}$ : a, $\mathbf{c}$ without ultrasound; b, d with ultrasound

welding arc is turned off at the different time. It is found that the equiaxed grain size around the fusion zone increases gradually with an increase in arc delay time (Fig. 3).

The second experiment that the welding current is increased after turning off the ultrasonic power reveals that the region of the equiaxed grain around the fusion zone disappears gradually with an increase in the welding current (Fig. 4).

The arc delay time and welding current are increased after turning off the ultrasonic power. As a result, the heat input is increased according to Eq. (1).

$Q=U I t$,

where $Q$ is the heat input, $U$ is the welding voltage, $I$ is the welding current and $t$ is the welding time.

The heat input for the S-2, S-3 and S-4 is bigger than that for the S-5, S-6 and S-7. According to previous analysis on the microstructure, it seems to be contradictory for the relation between the microstructure around the fusion zone and the heat input. Theoretically, the equiaxed grain size should be bigger, and column grain is more and more with an increase in heat input. However, there is no column grain around the fusion zone for the S-1, S-2, S-3 and S-4 compared with the S-6 and S-7. The reason is as follows: The welding current is constant and the welding time increases in the welding process for the S-1, S-2, S-3 and S-4. Although the welding time increases, the temperature could not be increased significantly due to a heat balance in weld pool. Thus, the equiaxed grain size increases gradually and the column grain is not produced. A heat balance is destroyed resulting in a significant increase in temperature in the weld pool when the welding current increases for the S-5, S-6 and S-7; thus, the microstructure around the fusion zone is changed significantly and the grain is changed from the equiaxed grain to the column grain with an increase in heat input. The welding current is constant in 


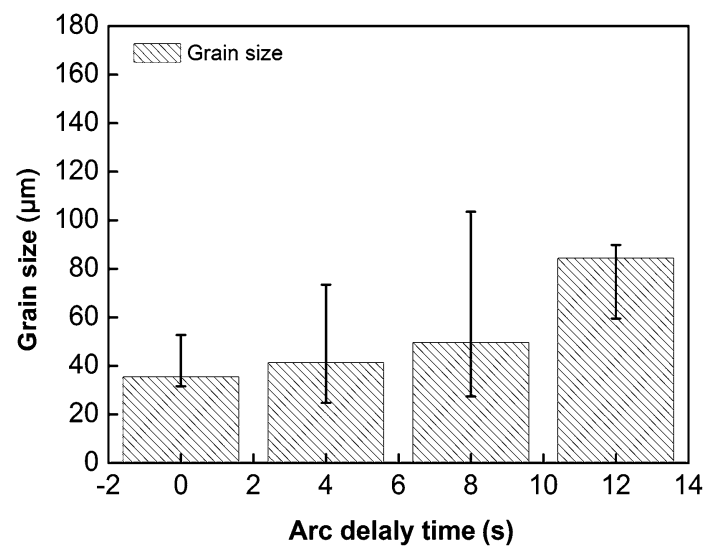

Fig. 3 Equiaxed grain size around the fusion zone for the $2195 \mathrm{Al}-\mathrm{Li}$ alloy with different arc delay time

the welding process for the S-1, S-2, S-3, S-4 and S-5, and the relation between the equiaxed grain size and the heat input could be contrasted with these five experiments. It is obvious that the equiaxed grain size increases gradually as the increase in heat input (Fig. 5).

\subsubsection{Effect of Ultrasonic Cavitation on Nucleation Temperature}

An instantaneous high pressure could be induced by the ultrasonic cavitation. The maximum pressure could be described by Eq. (2) [24].

$P_{\max }=P_{\gamma}\left[\frac{P_{\mathrm{m}}(\gamma-1)}{P_{\gamma}}\right]^{\frac{\gamma}{\gamma-1}}$,

where $P_{\max }$ is the maximum pressure, $P_{\gamma}$ is the vapor pressure in the cavitation bubble, $P_{\mathrm{m}}$ is the acoustic pressure amplitude acting on the surface of cavitation bubble and $\gamma$ is the ratio of specific heat.

The relation between $P_{\max }$ and $P_{\mathrm{m}}$ is shown in Fig. 6a in a condition where $P_{\gamma}$ is $6.8 \times 10^{3} \mathrm{~Pa}$ and $\gamma$ is $4 / 3$. The results reveal that $P_{\max }$ is increased with an increase in $P_{\mathrm{m}}$.

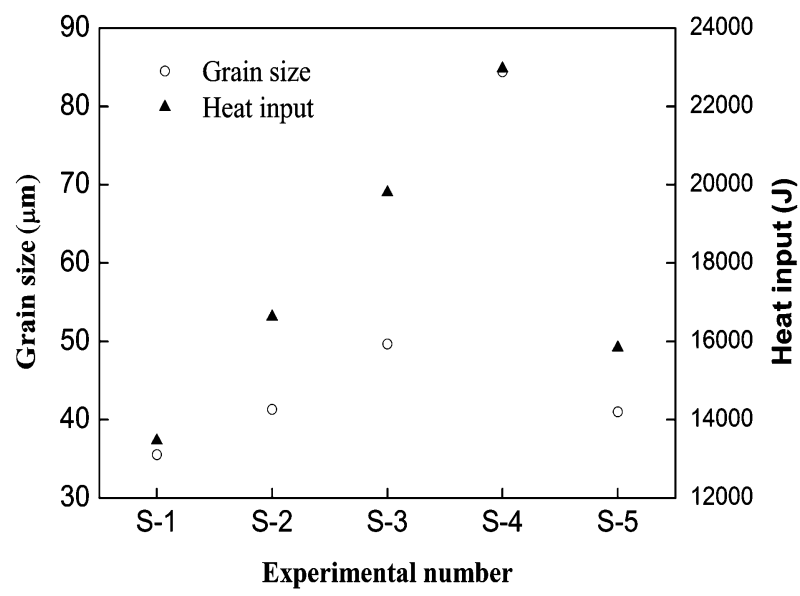

Fig. 5 Relation between the equiaxed grain size around the fusion zone of $\mathrm{Al}-\mathrm{Li}$ alloy and the heat input

The collapse of bubble can generate extremely large pressure spikes, and the large pressure could increase the freezing temperature of the $\mathrm{Al}-\mathrm{Li}$ alloy according to the Clausius-Clapeyron Equation.

$\frac{\mathrm{dT}_{\mathrm{m}}}{\mathrm{d} p}=\frac{T_{\mathrm{m}}\left(V_{\mathrm{L}}-V_{\mathrm{s}}\right)}{L}$,

where $T_{\mathrm{m}}$ is the freezing temperature, $P$ is the melting pressure, $V_{\mathrm{L}}$ and $V_{\mathrm{S}}$ are the specific volumes of the liquid and solid phases, respectively, and $L$ is the latent heat of solidification. The relation between the freezing temperature and the acoustic pressure is shown in Fig. $6 \mathrm{~b}$ in a condition where $V_{\mathrm{L}}$ is $0.418 \mathrm{~cm}^{3} / \mathrm{g}, V_{\mathrm{S}}$ is $0.36 \mathrm{~cm}^{3} / \mathrm{g}$ and $L$ is $400 \mathrm{~J} / \mathrm{g}$. Point $\mathrm{A}$ is the freezing temperature at the standard atmosphere pressure, and the value is about $923.15 \mathrm{~K}$. The freezing temperature could be improved about $135 \mathrm{~K}$ when the pressure of melt is $1000 \mathrm{MPa}$.

The expansion of the cavity could also reduce the surface temperature of the bubble so that the undercooling degree is increased [15]. Thus, ultrasonic cavitation increases the undercooling degree of nucleation and promotes nucleation by improving the nucleation temperature and decreasing the local temperature of melt.
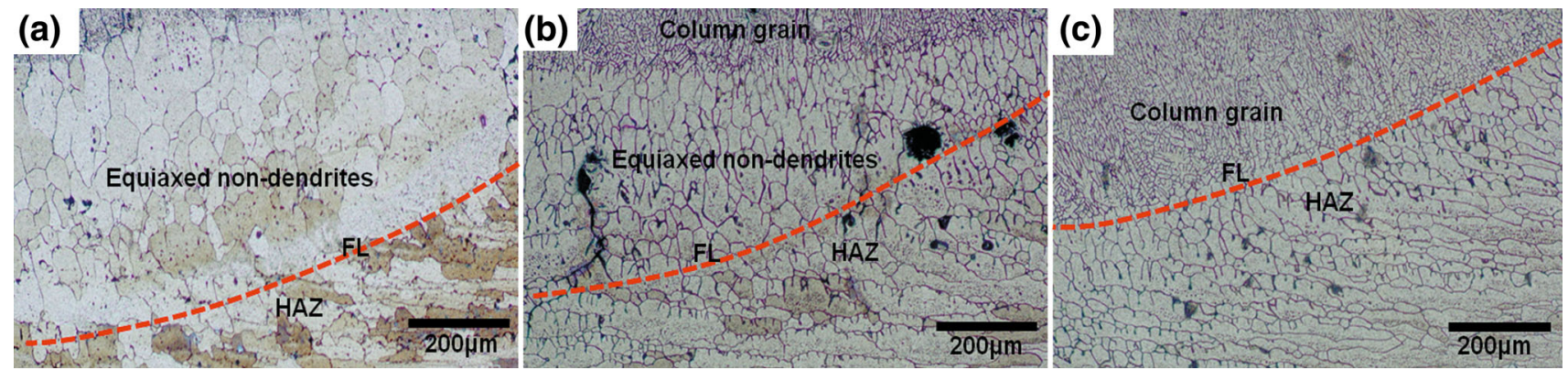

Fig. 4 Microstructure around the fusion zone for the $2195 \mathrm{Al}-\mathrm{Li}$ alloy with different welding currents a $60 \mathrm{~A}$, b $70 \mathrm{~A}, \mathbf{c} 75 \mathrm{~A}$ 

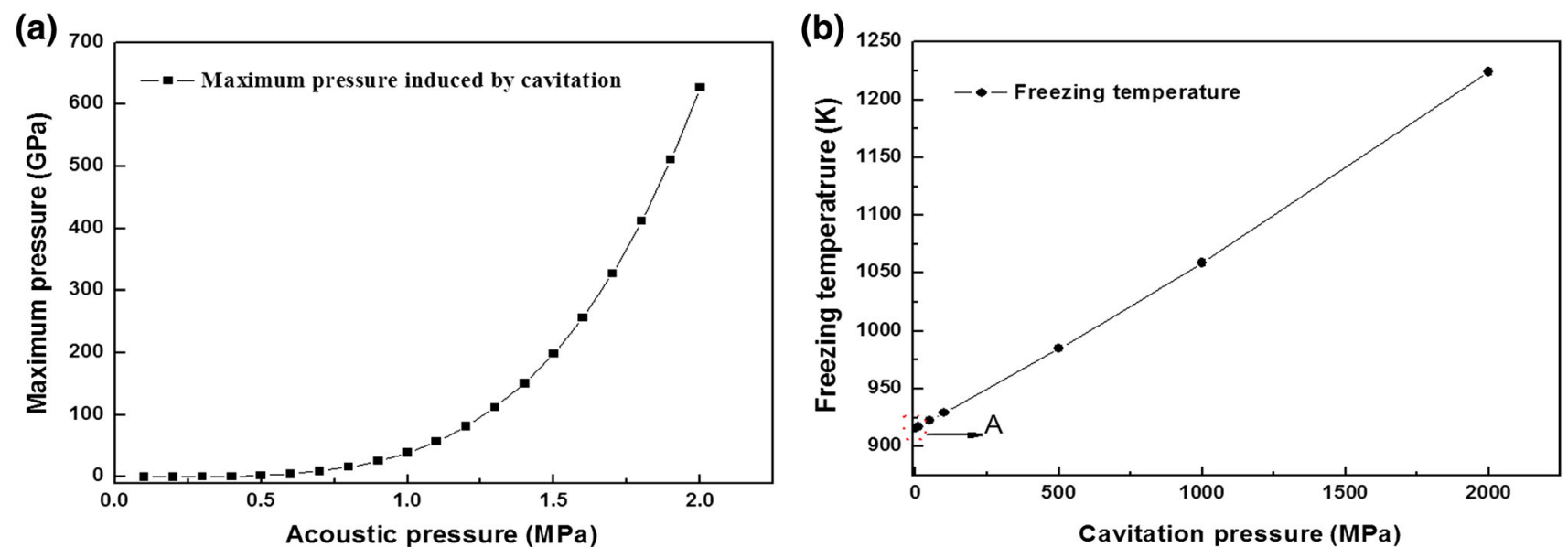

Fig. 6 a Relation between the maximum pressure and the acoustic pressure; $\mathbf{b}$ relation between the freezing temperature and the cavitation pressure

\subsubsection{Model on Heterogeneous Nucleation in the Ultrasonic Field}

Ultrasonic cavitation could improve the nucleation temperature, and the freezing temperature is increased from $T_{0}$ to $T_{1}$. Ultrasonic cavitation could also decrease the local temperature of melt. As these results, heterogeneous nucleation could start around the fusion zone before turning off the welding arc in a temperature range from $T_{0}$ to $T_{1}$ (Fig. 7). The crystal nucleus could be melted, and the number of crystal nucleus decreases gradually with an increase in heat input after turning off the ultrasonic power. Thus, the grain around the fusion zone is changed gradually from the equiaxed grain to the column grain with an increase in heat input after turning off the ultrasonic power.

\subsection{Effects of Welding Current and Ultrasonic Amplitude on Heterogeneous Nucleation of the Al-Li Alloy}

Effects of welding current and ultrasonic amplitude on heterogeneous nucleation of $\mathrm{Al}-\mathrm{Li}$ alloy were evaluated by assessing the effects of welding current and ultrasonic amplitude on equiaxed grain size around the fusion zone. The results show that the grain size increases gradually with the increase in welding current (Fig. 8a). This result is similar to the Barbosa's research result who suggests that the grain size increases gradually with ultrasonic treatment temperature [15]. The grains are refined significantly after applying ultrasonic treatment; however, the grain size is not further refined with an increase in ultrasonic amplitude, and the grain size becomes larger when the ultrasonic amplitude is equal to $11.4 \mu \mathrm{m}$ (Fig. 8b).

The equiaxed grain size around the fusion zone increases with an increase in welding current. This suggests that

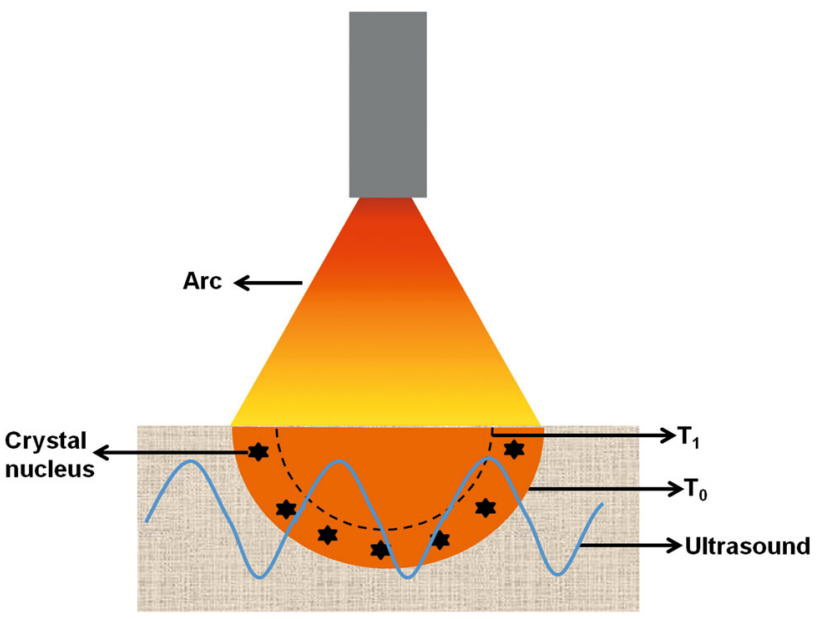

Fig. 7 Schematic diagram of the heterogeneous nucleation in the TIG weld pool of the $2195 \mathrm{Al}-\mathrm{Li}$ alloy with ultrasound

the role of ultrasound on grain refinement decreases gradually with the increase in welding current. The possible reason is as follows: heterogeneous nucleation could start in advance before turning off the welding arc when applying the ultrasonic treatment. The higher welding current could result in higher heat input, and the average temperature in the weld pool increases. More crystal nuclei could be melted under the influences of the flow and the high weld pool temperature, resulting in a small nucleation rate in the weld pool. Thus, the equiaxed grain size around the fusion zone increases with an increase in welding current. Increasing the ultrasonic amplitude does not result in a linear decrease in the equiaxed grain size. The equiaxed grain size increased significantly when the ultrasonic amplitude is $11.4 \mu \mathrm{m}$. This may be due to the nonlinearity of ultrasonic cavitation. An increase in ultrasonic power does not result in an equivalent increase in cavitation activity [25]. Thus, the heterogeneous nucleation 

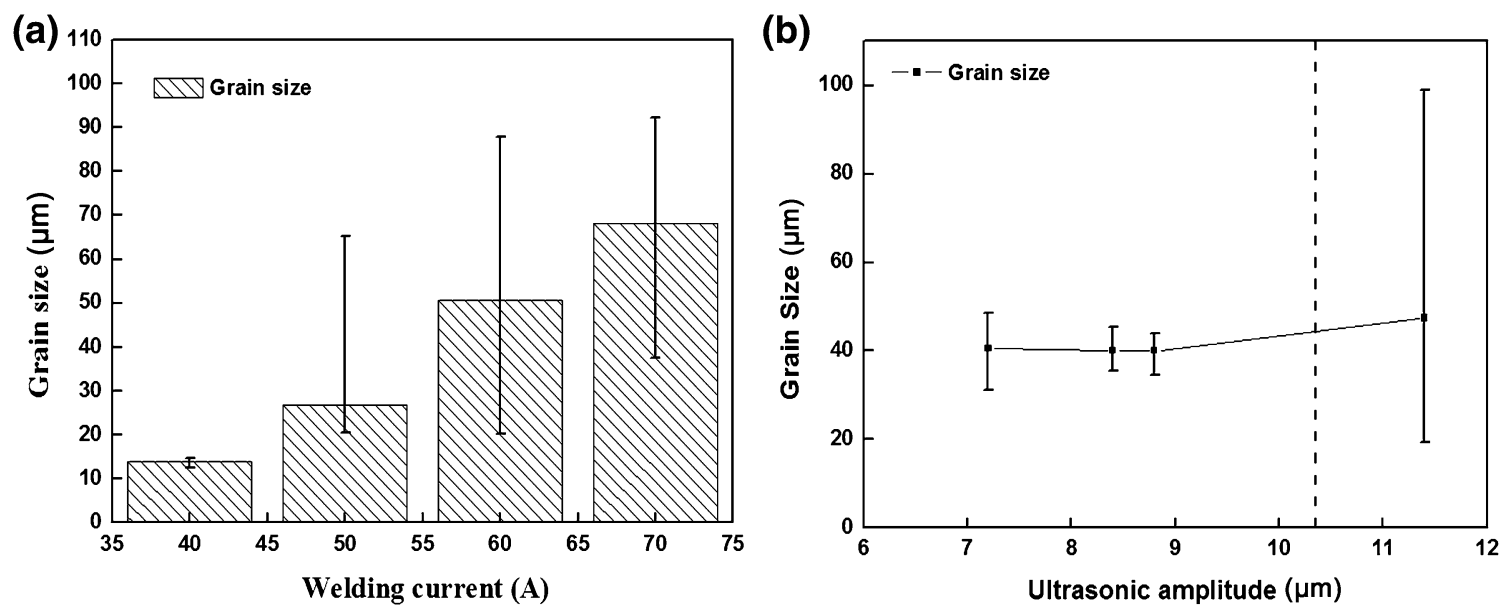

Fig. 8 Equiaxed grain size around the fusion zone of the 2195 Al-Li alloy: a with different welding currents; b with different ultrasonic amplitudes

rate could not be linearly increased with an increase in ultrasonic amplitude. As a result, the equiaxed grain size could not decrease linearly with an increase in ultrasonic amplitude.

According to the previous analysis, the effect of ultrasonic amplitude on the microstructure around the fusion zone is complex when the welding current is constant. There is a critical ultrasonic amplitude (Fig. 8b). The equiaxed grain size increases significantly when the ultrasonic amplitude is higher than the critical value. The critical ultrasonic amplitude represents the nonlinearity of acoustic field in the weld pool. When the cavitation effect occurs, the cavitation initiates more cavitation bubbles. Bubbles are mechanical oscillators so that wave dispersion is expected. They oscillate nonlinearly for large-amplitude drivings, so that waves should be nonlinear. Finally, they dissipate mechanical energy by various processes, which should produce wave attenuation [26]. The energy attenuation decreases the acoustic pressure in TIG weld pool; thus, the cavitation activity is also decreased. The critical ultrasonic amplitude could be obtained by combining the numerical simulation of the nonlinear ultrasonic pressure wave propagation in the TIG weld pool and the welding experiment with different ultrasonic amplitudes. The computational pressure value will decrease in the TIG weld pool when the critical ultrasonic amplitude is achieved. The influencing mechanism of ultrasonic amplitude on heterogeneous nucleation in TIG welding of Al-Li alloy is still unclear, thus needs to be further investigated in the future research.

\section{Conclusions}

1. The ultrasound could promote heterogeneous nucleation in the TIG weld pool. As a consequence, the grains around the fusion zone for the $2195 \mathrm{Al}-\mathrm{Li}$ alloy are changed from the column grain to the equiaxed grain after applying ultrasonic treatment.

2. The influencing mechanism of ultrasound on heterogeneous nucleation in the TIG weld pool of the 2195 $\mathrm{Al}-\mathrm{Li}$ alloy is investigated. The main mechanism is that ultrasound could promote heterogeneous nucleation by improving the nucleation temperature and decreasing the local temperature of melt.

3. Effects of the welding current and the ultrasonic amplitude on heterogeneous nucleation rate in the TIG weld pool of the $2195 \mathrm{Al}-\mathrm{Li}$ alloy are investigated. Heterogeneous nucleation rate around the fusion zone decreases with an increase in welding current. The relation between heterogeneous nucleation rate and the ultrasonic amplitude is complex, and the relation is nonlinear.

Acknowledgments This project was supported by the Key Program of the National Natural Science Foundation of China (Grant No. 51435004).

\section{References}

[1] G.E. Totten, D.S. MacKenzie, Handbook of Aluminum, vol. 1, Physical Metallurgy and Processes (Marcel Dekker Inc, New York, 2003)

[2] B.S. Murty, S.A. Kori, M. Chakraborty, Int. Mater. Rev. 47, 3 (2002)

[3] T.M. Wang, Z.N. Chen, H.W. Fu, L. Gao, T.J. Li, Mater. Sci. Eng., A 549, 136 (2012)

[4] O.V. Abramov, Ultrasound in Liquid and Solid Metals (CRC Press, Boca Raton, 1994)

[5] A. Ramirez, M. Qian, B. Davis, T. Wilks, D.H. StJohn, Scr. Mater. 59, 19 (2008)

[6] X. Jin, B.Q. Fu, C.L. Zhang, W. Liu, Acta Metall. Sin. (Engl. Lett.) 28, 1149 (2015)

[7] L.B. He, P. Yang, L.M. Li, M.S. Wu, Ultrasonics 54, 2178 (2014) 
[8] T. Watanabe, M. Shiroki, A. Yanagisawa, T. Sasaki, J. Mater. Process. Technol. 210, 1646 (2010)

[9] T. Yuan, S. Kou, Z. Luo, Acta Mater. 106, 144 (2016)

[10] M. Qian, A. Ramirez, A. Das, J. Cryst. Growth 311, 3708 (2009)

[11] H.R. Kotadia, A. Das, E. Doernberg, R. Schmid-Fetzer, Mater. Chem. Phys. 131, 241 (2011)

[12] B. Patel, P. Chaudhari, P. Bhingole, Mater. Lett. 66, 335 (2012)

[13] G. Wang, M.S. Dargusch, M. Qian, D.G. Eskin, D.H. Stjohn, J. Cryst. Growth 408, 119 (2014)

[14] M. Sha, S.S. Wu, L. Wan, Mater. Sci. Eng., A 554, 142 (2012)

[15] H. Puga, S. Costa, J. Barbos, S. Ribeiro, M. Prokic, J. Mater. Process. Technol. 211, 1729 (2011)

[16] V. Abramov, O. Abramov, V. Bulgakov, F. Sommer, Mater. Lett. 37, 27 (1998)

[17] T.V. Atamanenko, D.G. Eskin, L. Zhang, L. Katgerman, Metall. Mater. Trans. A 41, 2056 (2010)
[18] T.V. Atamanenko, D.G. Eskin, L. Katgerman, Mater. Sci. Forum 561-565, 987 (2007)

[19] H.J. Huang, Y.F. Xu, D. Shu, Y.F. Han, J. Wang, B.D. Sun, Trans. Nonferrous Metals Soc. China 24, 2414 (2014)

[20] B.L. Fu, G.L. Qin, X.M. Meng, Y. Ji, Y. Zou, Z. Lei, Mater. Sci. Eng., A 617, 1 (2014)

[21] J. Yan, M. Gao, G. Li, C. Zhang, X.Y. Zeng, M. Jiang, Int. J. Adv. Manuf. Technol. 66, 1467 (2013)

[22] R.G. Madhusudhan, A.G. Amol, J. Mater. Sci. 32, 4117 (1997)

[23] S.C. Chen, J.C. Huang, Mater. Sci. Technol. 15, 965 (1999)

[24] L.F. Mondolfo, Structure and Properties of Aluminum Alloys (Butterworths Press, London, 1976)

[25] I. Tzanakis, G.S.B. Lebon, D.G. Eskin, K.A. Pericleous, J. Mater. Process. Technol. 229, 582 (2016)

[26] O. Louisnard, Ultrason. Sonochem. 19, 56 (2012) 